Sudha Anupindi James Perumpillichira Diego Jaramillo Michael E. Zalis

Esther J. Israel

\section{Low-dose CT colonography in children: initial experience, technical feasibility, and utility}

Published online: 3 May 2005

(C) Springer-Verlag 2005

The online version of the original article can be found at http://dx.doi.org/10.1007/ s00247-004-1394-2

S. Anupindi $(\bowtie) \cdot J$. Perumpillichira

D. Jaramillo $\cdot$ M. E. Zalis

Department of Radiology,

Massachusetts General Hospital,

55 Fruit St., White 246,

Boston, MA 02115, USA

E-mail: sanupindi@partners.org

Tel.: + 1-617-7244207

Fax: +1-617-7268360

E. J. Israel

Department of Gastroenterology and Nutrition, Massachusetts General

Hospital, Boston, MA 02115, USA

\section{Pediatr Radiol (2005) 35:518 - 524}

The names of the authors should have been in the following order:

Sudha Anupindi · James

Perumpillichira · Diego Jaramillo .

Michael E. Zalis · Esther J. Israel 